\title{
PENGARUH FOOT MASSAGE DAN INHALASI AROMATERAPI LAVENDER TERHADAP TEKANAN DARAH DAN NYERI POST OPERASI MAYOR ELEKTIF
}

\author{
Effectiveness of Foot Massage and Inhalation Lavender Aromatherapy on Blood \\ Pressure And Pain of Major Elective Postoperative Patients
}

\author{
Agus Prasetyo*, Bejo Danang Saputra, Kiki Yulistiana \\ STIKES Al Irsyad Al Islamiyyah Cilacap \\ (Email :prasetyoagus163@gmail.com/081548881148)
}

\begin{abstract}
ABSTRAK
Pembedahan atau operasi adalah semua tindakan pengobatan yang menggunakan cara invasif dengan membuka atau menampilkan bagian tubuh yang dapat menimbulkan respon berupa nyeri yang dapat mempengaruhi tingkat nyaman seseorang. Hasil penelitian menunjukkan $50 \%$ keluhan nyeri pasca operasi tidak ditangani secara komprehensif dan fluktuasi tekanan darah pasca operasi biasanya terjadi karena berbagai faktor dalam tindakan pembedahan. Oleh sebab itu dibutuhkan upaya untuk melakukan pengobatan secara non farmakologi untuk mengurangi nyeri dan mengontrol tekanan darah misalnya dengan pemberian foot massage dan inhalasi aromaterapi lavender. Tujuan penelitian ini untuk mengetahui efektifitas foot massage dan inhalasi aromaterapi lavender terhadap tekanan darah dan nyeri pada pasien post operasi mayor elektif di RSUD Cilacap tahun 2019. Jenis penelitian ini adalah kuantitatif korelatif dengan metode pengambilan sampel purposive sampling sesuai kriteria inklusi yaitu sebanyak 34 orang. Desain penelitian quasi experiment dengan rancangan pretest-postest dengan kelompok kontrol dan menggunakan uji statistik Wilcoxon signed rank test. Hasil penelitian menunjukan bahwa sebelum diberikan intervensi rata-rata skala nyeri pasien 3,12 menurun menjadi 2,00 setelah diberikan intervensi. Terdapat pengaruh foot massage dan inhalasi aromaterapi lavender terhadap nyeri pasien post operasi mayor elektif $(p v=0,000)$.Tidak ada pengaruh foot massage dan inhalasi aromaterapi lavender terhadap tekanan darah sistole $(p v=0,559)$.
\end{abstract}

Kata Kunci: foot massage, inhalasi aromaterapi lavender, post operasi mayor elektif.

\begin{abstract}
Surgery are all treatment measures that use invasive methods by opening or displaying body parts, while $m$ ajor surgery is an operation that penetrates and shows the body cavity, including the skull, including bone surgery or significant anatomical damage or physiological function that can cause a response in the form of pain which can affect one's level of comfort. Therefore an effort is needed to carry out non-pharmacological treatments to reduce pain without causing side effects, for example by giving lavender aromatherapy foot massage and inhalation. The purpose of this study was to determine the effectiveness of foot massage and inhalation of lavender aromatherapy against pain reduction in patients post elective major surgery in Cilacap Hospital in 2019. This type of research is quantitative correlative with purposive sampling sampling method according to the inclusion criteria as many as 34 people. The study design was quasi-experimental with a pretestposttest design with the control group and using the Wilcoxon signed rank test statistical test. The results showed that before the intervention was given the average pain scale of patients 3.12 decreased to 2.00 after being given an intervention. There is the effect of foot massage and inhalation of lavender aromatherapy on pain in patients post elective major surgery in Cilacap Hospital in 2019 ( $p v=0,000)$. There is no effect of foot massage and inhalation of lavender aromatherapy on sistole blood pressure $(p v=0,559)$
\end{abstract}

Keywords: foot massage, inhalation of lavender aromatherapy, post elective major surgery. 


\section{PENDAHULUAN}

Pembedahan atau operasi adalah semua tindakan pengobatan yang menggunakan cara invasif dengan membuat sayatan, pada bagian tubuh yang akan ditangani, lalu dilakukan tindakan perbaikan dan diakhiri dengan penutupan dan penjahitan luka untuk mendiagnosa atau mengobati suatu penyakit, cedera atau cacat, serta mengobati kondisi yang sulit atau tidak mungkin disembuhkan hanya dengan obat-obatan sederhana (Perry, 2010)

Bedah mayor adalah tindakan bedah besar yang menggunakan anestesi umum/general anestesi yang merupakan salah satu bentuk dari pembedahan yang sering dilakukan dan memperlihatkan rongga badan, termasuk tengkorak, serta pembedahan tulang atau kerusakan signifikan dari anatomis atau fungsi faal (Amarillah, 2017)

Adapun bedah elektif adalah pembedahan dimana jika tidak dilakukan pembedahan (penundaan) tidak terlalu membahayakan pasien, dilakukan berdasarkan pada pilihan pasien, atau dengan kata lain jenis pembedahan yang sifatnya dapat direncanakan (Brunner and Suddarth, 2010)

Nyeri akibat pembedahan merupakan pengalaman yang tidak menyenangkan akibat dari kerusakan jaringan yang aktual dan potensial, atau menggambarkan kondisi terjadinya suatu kerusakan dan salah satu pemicu yang dapat meningkatkan level hormon stres seperti adrenokortikotropin, kortisol, katekolamin dan interleukin dan secara simultan dapat menurunkan pelepasan insulin dan fibrinolisis yang akan mperlambat proses penyembuhan luka paska pembedahan (Gian, 2017)

Salah satu intervensi keperawatan yang dapat dilakukan adalah manajemen nyeri yang menggunakan teknik farmakologi yang berkolaborasi dengan tim medis ataupun intervensi mandiri teknik nonfarmakologis.

Tekhnik non farmakologi komplementer dapat meningkatkan kenyamanan pasien serta mempercepat proses penyembuhan dan mempunai resiko yang sangat rendah, sebagai contoh terapi musik, relaksasi, tekhnik meditasi, massage, obat herbal, hipnotis terapi dan pijat refleksi. Massage efektif dalam memberikan relaksasi fisik dan mental, mengurangi nyeri dan meningkatkan keefektifan dalam pengobatan. Massage efektif dalam memberikan relaksasi fisik dan mental, mengurangi nyeri dan meningkatkan keefektifan dalam pengobatan. Massage pada daerah yang diinginkan selama 20 menit dapat merelaksasikan otot dan memberikan istirahat yang tenang dan kenyamanan serta 
terdapat $50 \%$ penurunan nyeri, kelelahan, stres / kecemasan, mual dan muntah pada klien paska operasi (Chanif, C., Petpichetchian, W., \& Chongchareon, 2013)

Foot massage therapy merupakan gabungan dari empat teknik masase yaitu effleurage (Mengusap), petrissage (memijit), Friction (menggosok) dan tapotement (menepuk). Kaki memiliki 7000 syaraf di setiap bagian sehingga mewakili seluruh organ - organ yang ada didalam tubuh. Foot massage merupakan mekanisme modulasi nyeri yang dipublikasikan untuk menghambat rasa sakit dan untuk memblokir transmisi impuls nyeri sehingga menghasilkan analgetik dan nyeri yang dirasakan setelah operasi diharapkan berkurang (Chanif, C., Petpichetchian, W., \& Chongchareon, 2013)

Selain dengan foot massage salah satu terapi yang efektif menurunkan nyeri adalah dengan aromaterapi. Aromaterapi merupakan tindakan terapeutik dengan menggunakan minyak esensial yang bermanfaat untuk meningkatkan keadaan fisik dan psikologi sehingga menjadi lebih baik Aromaterapi lavender merupakan tindakan terapeutik yang bermanfaat meningkatkan kondisi fisik dan psikologis. Secara fisik baik digunakan untuk mengurangi rasa nyeri, sedangkan secara psikologis dapat merilekskan pikiran, menurunkan ketegangan dan kecemasan serta memberi ketenangan karena komponen kimia utama yang dikandungnya adalah linail asetat, linalool yang memberikan rasa rileks. Uap lavender dihasilkan dari campuran air kurang lebih sesuai takaran yang sudah ada pada alat dengan aroma minyak essensial lavender sebanyak 5 tetes. Alat tersebut dapat digunakan maksimal selama 4 jam. Inhalasi dapat dilakukan berulang-ulang selama nyeri dirasakan (Primadiati R, 2002)

Hasil studi pendahuluan selama dua bulan terakhir, tercatat dari bulan Februari sampai dengan Maret 2019 pasien operasi mayor berkisar 43 orang yang masing-masing mengalami nyeri dalam rentang skala nyeri sedang sampai dengan berat. Berdasarkan latar belakang dari fenomena diatas peneliti tertarik untuk melakukan penelitian terkait efektifitas foot massage dan inhalasi aromaterapi lavender terhadap tekanan darah dan nyeri pada pasien post operasi mayor elektif diruang bedah RSUD Cilacap tahun 2019.

\section{METODE}

Jenis penelitian ini adalah kuantitatif korelatif dengan metode pengambilan sampel purposive sampling sesuai kriteria inklusi yaitu sebanyak 34 orang pasien operasi mayor 
elektif selain sistem muskuloskeletal ekstremitas bawah di bangsal bedah RSUD Cilacap yang dilaksanakan pada tanggal 30 April-20 Juni 2019. Desain penelitian quasi experiment dengan rancangan pretest-postest dengan kelompok kontrol.

Instrumen dalam penelitian ini adalah lembar observasi Wong Baker Faces Pain Rating Scale. Alat ukur ini digunakan untuk mengukur skala nyeri pasien. Analisis data yang dilakukan melalui editing, scoring, coding, processing, tabulating dan uji statistik.

Tindakan foot massage dilakukan oleh asisten peneliti dengan kualifikasi D3 fisioterapi selama 15 - 20 menit sekali sehari pada pagi hari dan aromaterapi lavender digunakan dengan alat diffuser untuk mengasilkan uap dari essence lavender dengan merk "AVA".

Analisis univariat dalam penelitian ini meliputi distribusi frekuensi jenis kelamin dan usia pasien, sedangkan analisis bivariat dilakukan terhadap kelompok intervensi dan kelompok kontrol dengan menggunakan uji statistik Wilcoxon signed rank test.

\section{HASIL}

$$
\begin{aligned}
& \text { Hasil data penelitian meliputi analisa } \\
& \text { univariat dan bivariat dibahas pada tabel } \\
& \text { dibawah ini : }
\end{aligned}
$$

1. Karakteristik responden di RSUD Cilacap berdasarkan usia dan jenis kelamin.

Tabel 1. Karakteristik responden berdasarkan usia dan jenis kelamin.

\begin{tabular}{llcc}
\hline No & Karakteristik & $\begin{array}{c}\text { Frekuensi } \\
(\mathbf{n = 3 4 )}\end{array}$ & $\begin{array}{c}\text { Presentase } \\
(\mathbf{\%})\end{array}$ \\
\hline 1 & Jenis Kelamin & & \\
& a. Laki laki & 15 & 44,1 \\
& b. Perempuan & 19 & 55,9 \\
\hline 2 & Usia & & \\
& a. 20 - 40 tahun & 17 & 50 \\
& b. $41-60$ tahun & 17 & 50 \\
& Jumlah & 34 & 100 \\
\hline
\end{tabular}

Berdasarkan tabel 1. dapat dilihat bahwa pasien post operasi mayor elektif berdasarkan jenis kelamin, terdapat sebagian besar perempuan dengan jumlah 19 orang $(55,9 \%)$ di bandingkan dengan laki-laki yang berjumlah 15 orang $(44,1 \%)$, sedangkan rentang usia pasien yang berada pada 20-40 dan 41-60 tahun sama jumlahnya masing-masing 17 orang $(50 \%)$.

2. Hasil uji hipotesis variabel nyeri post operasi mayor elektif.

Tabel 2.1.Descriptive statistic (Experimental Group)

\begin{tabular}{cccccc}
\hline $\begin{array}{c}\text { Intensitas } \\
\text { Nyeri }\end{array}$ & N & Mean & $\begin{array}{c}\text { Std } \\
\text { Dev }\end{array}$ & Min & Max \\
\hline $\begin{array}{l}\text { Pre test } \\
\text { intervensi }\end{array}$ & 17 & 3.12 & .485 & 2 & 4 \\
Post test & 17 & 2.00 & .791 & 1 & 3 \\
\hline
\end{tabular}


intervensi

Berdasarkan hasil pada tabel 2.1 menunjukan rata-rata (Mean) penurunan intensitas nyeri dari rata-rata 3,12 menjadi 2,00.

Tabel 2.2. The statisctic ${ }^{a}$ (experimental group)

\begin{tabular}{lc}
\hline \multicolumn{2}{c}{$\begin{array}{c}\text { PreTest intervensi - Post Test } \\
\text { Intervensi }\end{array}$} \\
\hline $\mathbf{Z}$ & $-3.578^{\mathrm{b}}$ \\
Asymp. Sig. & .000 \\
(2tailed) & \\
\hline
\end{tabular}

Dalam uji Wilcoxon signed rank test pada kelompok intervensi didapatkan $p v=0,000<$ dari 0,05 menunjukkan $H o$ ditolak yang berarti $\mathrm{Ha}$ diterima. Artinya bahwa ada perbedaan intensitas nyeri yang signifikan setelah pemberian foot massage dan inhalasi aromaterapi lavender.

Tabel 2.3. Descriptive statistic (Control Group)

\begin{tabular}{cccccc}
\hline $\begin{array}{c}\text { Intensitas } \\
\text { Nyeri }\end{array}$ & $\mathbf{N}$ & Mean & $\begin{array}{c}\text { Std } \\
\text { Dev }\end{array}$ & Min & Max \\
\hline $\begin{array}{l}\text { Pre test } \\
\text { intervensi }\end{array}$ & 17 & 3.35 & .702 & 2 & 4 \\
$\begin{array}{l}\text { Post test } \\
\text { intervensi }\end{array}$ & 17 & 3.29 & .849 & 1 & 4 \\
\hline
\end{tabular}

Berdasarkan hasil pada tabel 2.3 menunjukan penurunan nilai rata- rata (Mean) intensitas nyeri pasien post operasi mayor elektif dari 3,35 menjadi 3,29.
Tabel 2.4. The statisctic ${ }^{\mathrm{a}}$ (control group)

\begin{tabular}{lc}
\hline \multicolumn{2}{c}{$\begin{array}{c}\text { PreTest intervensi - Post Test } \\
\text { Intervensi }\end{array}$} \\
\hline $\mathbf{Z}$ & $-1.000^{\mathrm{b}}$ \\
$\begin{array}{l}\text { Asymp. Sig. } \\
\text { (2tailed) }\end{array}$ & .317 \\
\hline
\end{tabular}

Dalam uji Wilcoxon signed rank test pada tabel 2.4 pada kelompok kontrol didapatkan Hasil uji statistik diperoleh $p v=0,317>$ dari 0,05 menunjukkan Ho diterima yang berarti $\mathrm{Ha}$ ditolak. Artinya bahwa tidak ada perbedaan intensitas nyeri post operasi mayor elektif yang signifikan pada kelompok kontrol.

3. Hasil uji hipotesis variabel tekanan darah Tabel 3. The statisctic ${ }^{a}$ (experimental and control group)

\begin{tabular}{lll}
\hline & $\begin{array}{l}\text { TD sistole post } \\
\text { test - pre test } \\
\text { intervensi }\end{array}$ & $\begin{array}{l}\text { TD sistole post } \\
\text { test - pre test } \\
\text { kontrol }\end{array}$ \\
\hline $\mathbf{Z}$ & $-.587^{\mathrm{b}}$ & $-.827^{\mathrm{b}}$ \\
$\begin{array}{l}\text { Asymp. Sig. } \\
\text { (2tailed) }\end{array}$ & .559 & .408 \\
\hline
\end{tabular}

Dalam uji Wilcoxon signed rank test pada tabel 3 pada kelompok intervensi didapatkan Hasil uji statistik diperoleh tekanan darah sistole $p v=0,559>0,05$ dan pada kelompok kontrol $p v=0,408>0,05$ menunjukkan Ho diterima yang berarti $\mathrm{Ha}$ ditolak. Artinya bahwa tidak ada perbedaan perlakuan penelitian terhadap tekanan darah post operasi mayor elektif. 


\section{PEMBAHASAN}

Hasil penelitian ini sejalan dengan penelitian yang dilakukan oleh Fitria (2014) yang berjudul efektifitas tekhnik relaksasi progresif terhadap intensitas nyeri pada pasien pasca laparatomi dengan jumlah sampel 15 orang, 7 orang berjenis kelamin laki-laki $(46,7 \%)$ dan 8 orang perempuan $(53,3 \%)$.

Wanita lebih sering terkena beberapa jenis penyakit karena faktor gen dan hormon. Wanita lebih beresiko terkena penyakit kritis karena perbedaan dan fluktuasi hormon yang berlebihan, serta gaya hidup dan pola makan yang tidak sehat. (Dwinanda, A. R., Wijayanti, A. C., \& Werdani, 2017)

Pasien pada penelitian ini sebagian besar dapat diklasifikasikan dalam kategori usia produktif pada penelitian ini. Pada usia tersebut adalah usia produktif untuk bekerja, dan melakukan banyak aktivitas, karena gaya hidup kurang sehat, tekanan pekerjaan dan perubahan hormon menyebabkan tubuh rentan terserang berbagai penyakit. Semakin bertambahnya usia, maka fungsi fisiologis mengalami penurunan akibat proses degeneratif, sehingga menjadi salah satu indikator menurunnya daya tahan tubuh pada setiap orang, hal ini memicu timbulnya berbagai penyakit (Buletin jendela data dan informasi kesehatan, 2013).
Hasil penelitian ini merujuk sesuai pendapat yang dikemukakan oleh Perry, (2006) yang menyatakan massage yang dilakukan pada daerah yang diinginkan selama 20 menit dapat merelaksasikan otot dan memberikan istirahat yang tenang dan kenyamanan serta terdapat $50 \%$ penurunan nyeri, kelelahan, kecemasan, pada klien paska operasi.

Hasil penelitian juga sejalan dengan penelitian yang dilakukan oleh Nila, (2016) dengan judul Pengaruh foot massage terhadap penurunan skala nyeri pada pasien post operasi laparatomi diruang rawat inap RSUP Dr.M.Djamil Padang yang menyatakan bahwa ada pengaruh pemberian foot massage terhadap penurunan intensitas nyeri pasien post operasi laparotomy setelah diberikan terapi 1 kali pelaksanaan selama 20 menit, dan menunjukan bahwa sebelum diberikan foot massage rata- rata skala nyeri 5,00 menjadi 2,42. Penelitian ini juga didukung oleh penelitian yang dilakukan Abdelaziz, S. H. H., \& Mohammed (2014) yang menyatakan bahwa ada pengaruh pemberian Foot massage terhadap penurunan nyeri pasien post operasi kanker payudara dengan penurunan rata-rata sebelum intervensi $\quad 6,43$ menjadi $\quad 3,33$ menggunakan skala Visual Analog Scale. 
Kaki adalah fokus alami untuk penyembuhan, karena setiap bagian dipersarafi dengan 7000 ujung saraf (Bright, 2001). Telah dipahami bahwa foot massage dapat mendorong pelepasan terminal saraf dengan meningkatkan modulasi nyeri, karena setiap gerakan akan merangsang serabut saraf (serat A-beta) selanjutnya impuls akan dikirimkan ke saraf pusat. Sistem kontrol gerbang diaktifkan melalui interneuron penghambatan, sedangkan interneuron rangsang terhambat, sehingga menutup gerbang dan pesan rasa sakit tidak ditransmisikan ke system saraf pusat (Chanif, C., Petpichetchian, W., \& Chongchareon, 2013)

Penelitian ini juga sejalan dengan penelitian yang dilakukan oleh Wahyuningsih (2014) yang berjudul "Efektifitas aromaterapi lavender dan massage effleurage terhadap penurunan nyeri fase aktif kala 1 ibu bersalin primigravida di PONEK RSUD Karang Anyar" yang mengatakan adanya penurunan rata- rata skala nyeri sebesar 2,938 poin dari skala sebelumnya setelah diberikan intervensi inhalasi aromaterapi lavender dan massage effleurage.

Aromaterapi lavender mengandung komponen kimia utama linail asetat dan linalool yang dapat mempengaruhi limbic system di otak yang merupakan pusat emosi, suasana hati atau mood untuk menghasilkan bahan neurohormon endorphin dan encephalin yang bersifat sebagai penghilang rasa sakit (Wahyuningsih, 2014)

Hasil penelitian pada variabel tekanan darah dapat disebabkan pengaruh dari jenis anastesi yag diberikan. Masta, GAAP., Suranadi, IW (2016) melakukan penelitian tentang profil penurunan tekanan darah pasca induksi dengan anastesi umum di RSUP Sanglah 2016.

Hasil penelitian tersebut menunjukkan pasca induksi di dapatkan penurunan parameter hemodinamik pada tekanan darah sistolik 10,42 $\%$, kemudian tekanan darah diastolik menurun sebesar 2,5\%, mean arterial pressure (MAP) menurun sebesar 5,9\%. Adanya penurunan parameter hemodinamik baik tekanan darah sistolik, diastolik dan MAP pada pasien pasca induksi dengan propofol dan koinduksi fentanyl. Penelitian tersebut juga sejalan dengan hasil penelitian yang dilakukan Annisa Fadhlina (2010) yang menunjukkan anestesi intravena dengan menggunakan fentanil mempunyai efek hipotensi lebih sedikit dibanding dengan menggunakan petidin

\section{UCAPAN TERIMAKASIH}

Ucapan terimakasih yang pertama diucapkan kepada UPT PPM STIKES AlIrsyad Al-Islamiyyah Cilacap yang telah memfasilitasi publikasi artikel pada jurnal JKA ini. Yang kedua kepada Prodi S1 
Keperawatan yang telah memfasilitasi mahasiswa untuk terlibat dalam penelitian ini.

\section{KESIMPULAN}

Berdasarkan hasil penelitian dan pembahasan, maka dapat disimpulkan sebagai berikut:

1. Pasien post operasi mayor elektif di RSUD Cilacap saat dilakukan penelitian berdistribusi responden, jenis kelamin paling banyak kategori perempuan, yaitu sebanyak $19(55,9 \%)$ responden.

2. Rata-rata tingkat nyeri pasien post operasi mayor elektif sebelum diberikan intervensi adalah 3,12.

3. Rata-rata tingkat nyeri pasien post operasi mayor elektif sesudah diberikan intervensi adalah 2,00.

4. Terdapat hubungan antara pemberian foot massage dan inhalasi aromaterapi lavender terhadap penurunan intensitas nyeri pada pasien post operasi mayor elektif di RSUD Cilacap dengan $\mathrm{pv}=0,000(\alpha=0,05)$.

5. Tidak terdapat hubungan antara pemberian foot massage dan inhalasi aromaterapi lavender terhadap tekanan darah pada pasien post operasi mayor elektif di RSUD Cilacap dengan tekanan darah sistole kelompok intervensi didapatkan hasil uji statistik diperoleh $p v=0,559>0,05$ dan pada kelompok kontrol $p v=0,408>0,0$.

\section{DAFTAR PUSTAKA}

Abdelaziz, S. H. H., \& Mohammed, H. E. (2014) 'Effect of foot massage on postoperative pain and vital signs in breast cancer patient', Journal of Nursing Education and Practice, 115, p. 4(8).

Amarillah, K. D. (2017) 'Hubungan Jenis

Operasi Besar dan Operasi Kecil Terhadap Tingkat Kecemasan Pasien Pra Operasi di Rumah Sakit PKU Muhammadiyah Gamping.'

Annisa Fadhlina (2010) 'Perbandingan Perubahan Tekanan Darah Dan Laju Nadi Antara Pemberian Petidin dan Fentanil Sebagai Premedikasi Anastesi. Fakultas Kedokteran, Universitas Sebelas Maret, Surakarta.' Bright, M. A. (2001) Holistic health and healing. Philadelphia: PA: Davis Company.

Brunner and Suddarth (2010) Text Book Of Medical Surgical Nursing. Jakarta: EGC.

Buletin jendela data dan informasi kesehatan (2013) 'No Title'. Available 
at:

http:

//www.depkes.go.id/resources/download

/pusdatin/profil-kesehatan-

indonesia/profil-kesehatan-indonesia-

2013.pdf.

Chanif, C., Petpichetchian, W., \& Chongchareon, W. (2013) 'Does footmassage relieve acute postoperative pain? A literature review', Nurse Media Journal of Nursing, 3(1), pp. 483-497.

Dwinanda, A. R., Wijayanti, A. C., \& Werdani, K. E. (2017) 'Hubungan antara Pendidikan Ibu dan Pengetahuan Responden dengan Pernikahan Usia Dini', Jurnal Kesehatan Masyarakat Andalas, 10(1), pp. 76-81.

Gian, H. (2017) Asuhan Keperawatan Pada Tn. A Dengan Laparatomy Eksplorasi Atas Indikasi Hernia Inguinalis dengan AplikasiI Teknik Relaksasi Musik Serta Optimalisasi Pelaksanaan Discharge Planning di Ruangan Bedah Pria RSUP DR. M. DJAMIL PADANG (Doctoral dissertation, Un. Universitas Andalas.

Masta, GAAP., Suranadi, IW., D. D. (2016) 'Profil penurunan tekanan darah pasca induksi dengan anastesi umum di RSUP Sanglah', E-Jurnal Medika Udayana, Vol 7 No.5, pp. 217 - 220.
Nila, K. (2016) Pengaruh Foot Massage Therapy Terhadap Penurunan Skala Nyeri Pada Pasien Post Operasi Laparotomi Diruang Rawat Inap Bedah RSUP Dr.M.DJAMIL PADANG (Doctoral dissertation, ), Universitas Andalas. Available at: https://scholar.google.co.id/scholar?hl $=\mathrm{id} \&$ as_sdt=0\%2C5\&q=krisna + penga ruh+foot+massage $\& b \operatorname{tnG}=$.

Perry, P. (2010) Buku Ajar Fundamental Keperawatan. Edisi 4. Jakarta: EGC.

Primadiati R (2002) Aromaterapi Perawatan Alami untuk Sehat dan Cantik. Jakarta: PT Gramedia Pustaka Utama.

Wahyuningsih, M. (2014) 'Efektifitas Aroma Terapi Lavender dan Massage Effleurage Terhadap Tingkat Nyeri Persalinan Kala I Fase Aktif pada Primigravida.', Jurnal Penelitian Sekolah Tinggi Ilmu Keperawatan Kusuma Husada Surakarta. 
